\title{
Monitoring the Degradation of Tetracycline by Ozone in Aqueous Medium Via Atmospheric Pressure Ionization Mass Spectrometry
}

\author{
Ilza Dalmázio, Mariana O. Almeida, and Rodinei Augusti \\ Departamento de Química, Universidade Federal de Minas Gerais, Belo Horizonte, Brazil
}

Tânia M. A. Alves

Centro de Pesquisas Rene Rachou, Fundação Oswaldo Cruz, Belo Horizonte, Brazil

\begin{abstract}
The degradation of tetracycline (1) by ozone in aqueous solution was investigated. High performance liquid chromatography (HPLC), UV-visible spectroscopy (UV-Vis), and total organic carbon (TOC) analyses revealed that although tetracycline was quickly consumed under this oxidative condition, it did not mineralize at all. Continuous monitoring by electrospray ionization mass spectrometry in the positive ion mode, ESI(+)-MS, revealed that tetracycline (1), detected in its protonated form $\left([\mathbf{1}+\mathrm{H}]^{+}\right)$of $\mathrm{m} / \mathrm{z} 445$, reacted to yield almost exclusively two unprecedented oxidation products ( 2 and 3 ) via a net insertion of one and two oxygen atoms, respectively. Compound 2, suggested to be formed via an initial 1,3-dipolar cycloaddition of ozone at the C11a-C12 double-bond of $\mathbf{1}$, and Compound 3, proposed to be produced via a subsequent ozone attack at the C2-C3 double-bond of 2 , were detected in their protonated forms in the ESI(+)-MS, i.e., $[2+\mathrm{H}]^{+}$of $m / z 461$ and $[3+\mathrm{H}]^{+}$of $m / z 477$, and were further characterized by ESI(+)-MS ${ }^{n}$. LC-APCI(+)-MS (liquid chromatography coupled with atmospheric pressure chemical ionization mass spectrometry in the positive ion mode) experiments corroborated the results. (J Am Soc Mass Spectrom 2007, 18, 679-687) () 2007 American Society for Mass Spectrometry
\end{abstract}

$\mathrm{P}$ harmaceuticals are now recognized as a new class of pollutants and have been the subject of growing concern and scientific interest [1]. Urban wastewaters and effluents from sewage treatment plants (STP) are continuously contaminated by inappropriate disposal of several drugs [2], which results in their introduction to a wide range of environmental matrixes, including surface, ground, and drinking water, as well as soils $[3,4]$.

Early inquiries focused predominantly on the origins and occurrence of pharmaceuticals in the environment but, more recently, the application of more efficient water and wastewater treatments, especially advanced oxidative processes (AOP) [5, 6], has attracted the foremost attention [7]. The efficient removal of drugs from effluents is thus especially relevant owing to their toxic effects on several aquatic organisms [8]. Ozonation has been proposed to be an appropriate means to promote the degradation of pharmaceuticals in water and wastewaters [9-11]. The application of ozonation to remediate the obnoxious odors of swine manure slurry has also been reported [12].

Published online January 17, 2007

Address reprint requests to Dr. Rodinei Augusti, Departamento de Química, Universidade Federal de Minas Gerais, Belo Horizonte/MG, Brazil, 31270-901. E-mail: augusti@ufmg.br
Tetracyclines, a well-known class of antibiotics, have been used in human and animal treatment against infectious diseases, as an additive to animal feeds (poultry, cattle, and swine), in aquaculture, and to inhibit fungal growth in fruit trees. In the mid-1990s, its estimated consumption in the United States and Europe was 5500 tons/y [13]. Residual tetracyclines, found in soils fertilized with animal slurry [14] and in several wastewater treatment facility (influent/effluent) samples [15], can induce the development of multiresistant bacterium strains [16].

Atmospheric pressure ionization (API) methods, such as electrospray ionization (ESI) and atmospheric pressure chemical ionization (APCI), show a remarkable capacity to gently generate ionic species in the gas phase, usually without any undesirable side reaction [17-19]. These convenient features make these methods ideal to analyze compounds with a broad range of polarities and stabilities. Because of that, ESI-MS and APCI-MS have been extensively used to acquire relevant and unprecedented information about transient and unstable species formed during the course of a number of chemical reactions in aqueous solutions [20-22], including oxidation processes [23-27].

In addition to the degradation efficiency studies, the identification of byproducts arising from oxidation treatments, which can be more hazardous than the very 
precursors [28], is an important step in process assessment. Hence, in this work we examined the degradation of tetracycline (1) by ozone in aqueous solution. High performance liquid chromatography (HPLC), UV-visible spectroscopy (UV-Vis), and total organic carbon (TOC) analyses were performed to estimate the substrate degradation rate as well as to verify the presence of residual organic compounds in solution. Electrospray ionization mass and tandem mass spectrometry (ESI-MS and ESI-MS $^{\mathrm{n}}$, respectively) were applied to an in situ detection and characterization of a number of degradation products. LC-APCI-MS (liquid chromatography coupled with atmospheric pressure chemical ionization mass spectrometry) analyses were also employed to confirm the ESI-MS results.

\section{Experimental}

\section{Chemicals}

Tetracycline hydrochloride (TC-HCl) (Sigma-Aldrich, Milwaukee, WI), HPLC-grade acetonitrile (JT Baker, Phillipsburg, NJ), and oxalic acid (Sigma-Aldrich) were used without further purification. Double distilled water was used to prepare the solutions in all experiments. Ozone was produced by a generator (Eletro-Triozon, Florida/MS, Brazil) fed with pure synthetic air. The ozone flow rate, determined by the $\mathrm{KI}-\mathrm{Na}_{2} \mathrm{~S}_{2} \mathrm{O}_{3}$ titration method, was determined to be ca. $2.5 \mu \mathrm{mol} \cdot \mathrm{min}^{-1}$.

\section{Ozonation}

An aqueous solution of TC-HCl $\left(200 \mathrm{~mL}, 2 \times 10^{-4}\right.$ $\mathrm{mol} \cdot \mathrm{L}^{-1}$, natural $\mathrm{pH}=3$ ) was continuously bubbled with the ozone/air gas stream. Aliquots of the solution were collected at several reaction times and immediately sonicated for $1 \mathrm{~min}$ and analyzed by UV-Vis, HPLC-UV, TOC, ESI-MS, and LC-APCI-MS techniques.

\section{Analytical Methods}

$U V$-Vis spectroscopy. Absorbance measurements were performed using a Cary 50 Conc instrument (Varian, Mulgrave, Australia) equipped with a quartz cell with a path $1 \mathrm{~cm}$ long and using baseline correction. The scan rate was $300 \mathrm{~nm} \cdot \mathrm{min}^{-1}$ and the data point interval was $0.5 \mathrm{~nm}$.

HPLC-UV. The analyses were performed in an SPD10A instrument (Shimadzu, Kyoto, Japan) using a Hypersil C18 column (250 mm long, $4.6 \mathrm{~mm}$ i.d., $5 \mu \mathrm{m}$ particle size). The following operating conditions were employed: isocratic elution of acetonitrile $/ 0.01 \mathrm{~mol} \cdot \mathrm{L}^{-1}$ aqueous oxalic acid (1:1), flow rate of $1 \mathrm{~mL} \cdot \mathrm{min}^{-1}$, injection volume of $20 \mu \mathrm{L}$, and UV detector set up at 275 and $350 \mathrm{~nm}$.
TOC. The experiments were carried out in a TOC 5000A (Shimadzu) instrument at $680{ }^{\circ} \mathrm{C}$ using a platinum catalyst.

ESI-MS and ESI-MS ${ }^{n}$. The analyses were conducted in an LCQ Advantage (ThermoElectron, San Jose, CA) mass spectrometer operating in the positive ion mode with an electrospray ionization (ESI) source. Mass spectra were obtained as an average of 50 scans, each requiring $0.02 \mathrm{~s}$. The aliquots were directly injected into the ESI source at a flow rate of $5 \mu \mathrm{L} \cdot \mathrm{min}^{-1}$ by a micro syringe. ESI source conditions were as follows: heated capillary temperature $200{ }^{\circ} \mathrm{C}$; sheath gas $\left(\mathrm{N}_{2}\right)$ flow rate 20 units (ca. $0.30 \mathrm{~L} \cdot \mathrm{min}^{-1}$ ); spray voltage $4.5 \mathrm{kV}$; capillary voltage $25 \mathrm{~V}$; tube lens offset voltage $25 \mathrm{~V}$. For ESI-MS $^{n}$, the precursor ions were first isolated by applying an appropriate waveform across the end cap electrodes of the ion trap to resonantly eject all trapped ions, except ions of the $m / z$ ratio of interest. The isolated ions were then resonantly excited with a supplementary AC signal to cause collision-induced dissociation (CID). The relative collision energy was set to a value at which the product ions were produced in measurable abundance and varying from 18 to $40 \%$. The isolation width used in the $\mathrm{MS}^{\mathrm{n}}$ experiments was $1 \mathrm{~m} / \mathrm{z}$ unit.

LC-APCI-MS. The analyses were conducted in the same mass spectrometer as previously described, coupled with an APCI source operating in the positive ion mode. The mass spectra were obtained continuously during chromatographic run, each scan requiring $0.02 \mathrm{~s}$. The aliquots were introduced in the APCI source through the LC system fitted with a rheodyne injector (20 $\mu$ L loop) coupled with a Hypersil C18 column (250 mm length, $4.6 \mathrm{~mm}$ i.d., $5 \mu \mathrm{m}$ particle size) and a piston pump (Shimadzu 10AD). The LC operating conditions were as follows: isocratic elution of acetonitrile/0.01 $\mathrm{mol} \cdot \mathrm{L}^{-1}$ aqueous oxalic acid (6:4) and flow rate of 0.5 $\mathrm{mL} \cdot \mathrm{min}^{-1}$. APCI source conditions were as follows: discharge voltage $3 \mathrm{kV}$, discharge current $5 \mu \mathrm{A}$, capillary voltage $4 \mathrm{~V}$, vaporizer temperature $450{ }^{\circ} \mathrm{C}$, capillary temperature $150{ }^{\circ} \mathrm{C}$, sheath gas $\left(\mathrm{N}_{2}\right)$ flow rate 60 units (ca. $\left.0.90 \mathrm{~L} \cdot \mathrm{min}^{-1}\right)$, and auxiliary gas $\left(\mathrm{N}_{2}\right)$ flow rate 15 units (ca. $0.22 \mathrm{~L} \cdot \mathrm{min}^{-1}$ ).

\section{Results and Discussion}

\section{Degradation of Tetracycline}

The degradation of tetracycline (1) by ozone in aqueous solution was initially monitored by UV-Vis spectroscopy. Figure 1 shows the UV-Vis spectra of: (Figure 1a) the initial solution of tetracycline at $2.0 \times 10^{-4} \mathrm{~mol} \cdot \mathrm{L}^{-1}$, and (Figure $1 b-d$ ) aliquots withdrawn after successive reaction times of 20 to $120 \mathrm{~min}$.

As can be seen in Figure 1, the UV-Vis spectra undergo changes as the reaction proceeds. The absorbance at the two characteristic wavelengths of 1, i.e., ca. 275 and $360 \mathrm{~nm}$, continuously decreases, whereas a 


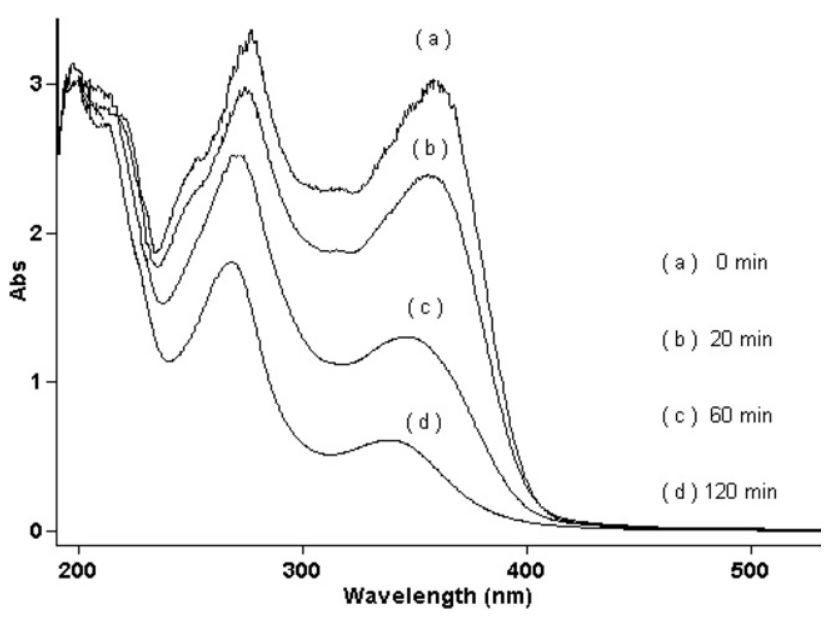

Figure 1. UV-Vis spectra of: (a) an aqueous solution of tetracycline at $2 \times 10^{-4} \mathrm{~mol} \mathrm{~L}^{-1}$, and (b)-(d) aliquots of the solution withdrawn after different times of reaction with ozone.

slight hypsochromic shift from 360 to $340 \mathrm{~nm}$ is clearly observed. These results thus indicate that under these reaction conditions, degradation products are continuously formed simultaneously to the consumption of tetracycline. It also seems that the chemical structures of these products are similar to that of tetracycline.

The HPLC-UV chromatograms obtained for aliquots collected at different reaction times are shown in Figure 2. It can be observed that the intensity of the tetracycline

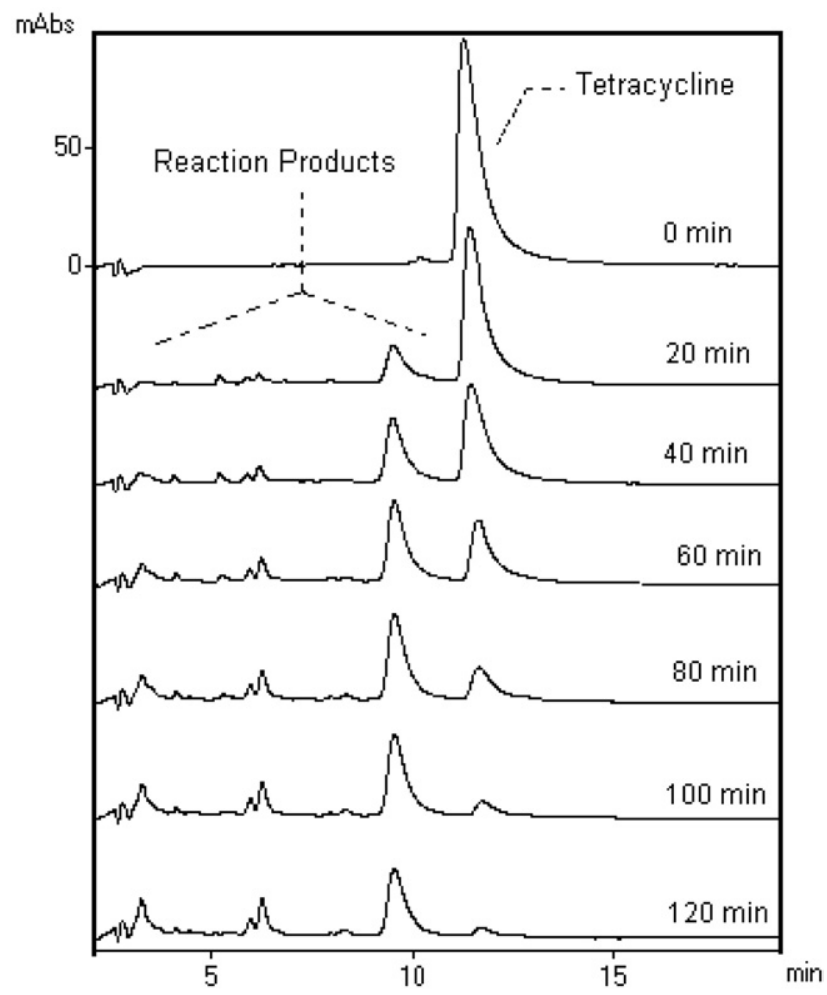

Figure 2. HPLC-UV $(275 \mathrm{~nm})$ chromatograms of aliquots taken at different times of reaction with ozone (0 to $120 \mathrm{~min}$ ). Note the appearance of new chromatographic peaks with retention times shorter than that of tetracycline (1).

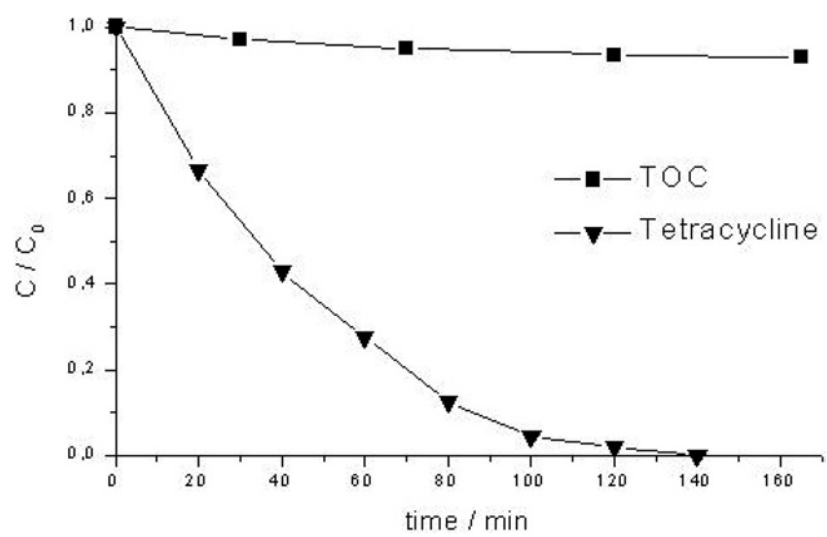

Figure 3. Normalized concentration $(\mathrm{C} / \mathrm{Co})$ of tetracycline (inverted filled triangle) as a function of time as monitored by HPLC-UV and total organic carbon (filled square) (TOC/TOCo) for aqueous $\mathrm{O}_{3}$ degradation. $\mathrm{C}_{0}=2 \times 10^{-4} \mathrm{~mol} \cdot \mathrm{L}^{-1}$ for $\mathrm{TOC}_{0}=$ $52.8 \mathrm{mg} \cdot \mathrm{L}^{-1}$.

peak (retention time of $12 \mathrm{~min}$ ) decreases as the reaction advances. Plots of the normalized tetracycline peak area and the solution total organic carbon (TOC) as a function of reaction time are shown in Figure 3. Observe that whereas tetracycline is almost fully consumed after a reaction time of $120 \mathrm{~min}$, only ca. $5 \%$ of TOC removal is observed. These results thus suggest that the ozonation promotes the degradation of tetracycline but does not lead to its mineralization (i.e., its conversion to small molecules such as $\mathrm{CO}_{2}, \mathrm{H}_{2} \mathrm{O}$, and $\mathrm{NH}_{3}$ ). Other organic compounds are formed in solution and their mineralization is likely quite slow, at least under such conditions. In fact, the new peaks detected during the HPLC monitoring (Figure 2) with retention times shorter than that of tetracycline strongly support such assumption. Also note that the intensities of these peaks increase continuously, thus indicating that these degradation products remain stable in solution upon their formation. The exception to this general behavior seems to be a degradation product that elutes in a retention time of ca. 10 min: its chromatographic peak reaches a maximum intensity after a reaction time of ca. $80 \mathrm{~min}$ and decreases afterwards. This result thus indicates that this product is continuously formed and subsequently converted into another product. These HPLC results also indicate that these degradation products have higher polarity than that of tetracycline, since they elute faster from the non-polar (C18) chromatographic column.

\section{ESI-MS Monitoring, ESI-MS ${ }^{n}$ Structural Evaluation, and LC-APCI-MS Analyses}

Figure 4 displays representative ESI mass spectra in the positive ion mode, ESI $(+)$-MS, of the tetracycline (1) aqueous solution acquired after 0,80 , and $140 \mathrm{~min}$ of ozone bubbling. In Figure $4 \mathrm{a}$, which displays the ESI(+)-MS of the initial solution of tetracycline (1) at $2.0 \times 10^{-4} \mathrm{~mol} \cdot \mathrm{L}^{-1}$, an intense and prominent ion of $\mathrm{m} / \mathrm{z}$ 445 , corresponding to $[\mathbf{1}+\mathrm{H}]^{+}$, is observed. Successive 


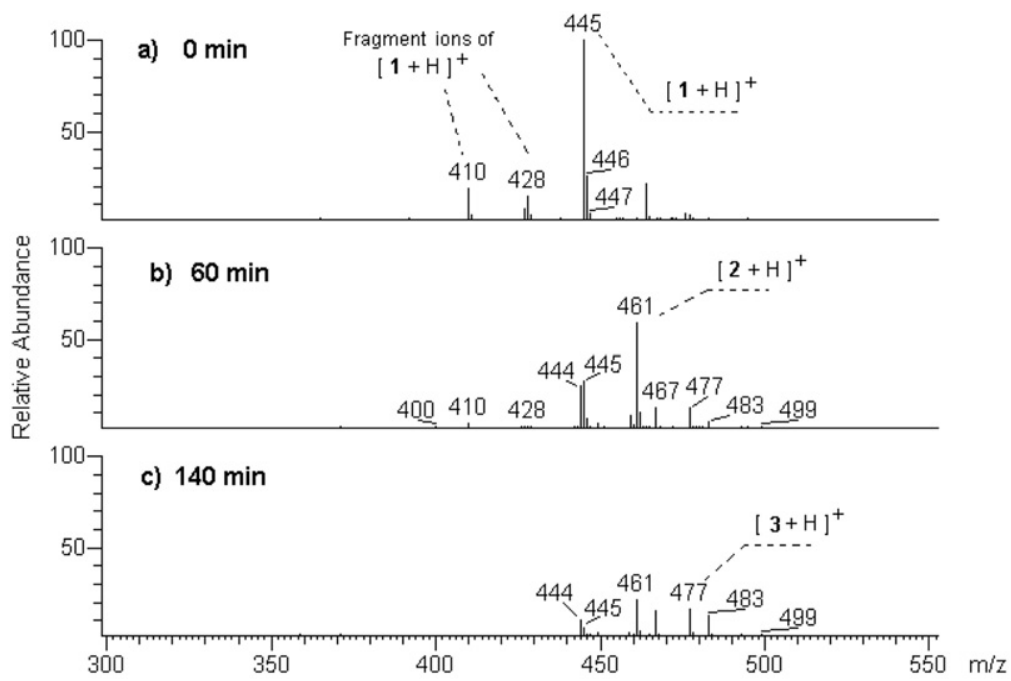

Figure 4. ESI(+)-MS monitoring of the reaction of tetracycline (1) with ozone in aqueous solution after: (a) $0 \mathrm{~min}$, (b) $60 \mathrm{~min}$, and (c) $140 \mathrm{~min}$. To allow a more consistent comparison, the abundances of all ions in the three spectra are relative to the abundance of the ion of $\mathrm{m} / \mathrm{z} 445$ in the first spectrum (a).

mass-selection of the main precursor ions and their fragmentation upon collision-induced dissociation (CID) yielded the following sequence: $[1+\mathrm{H}]^{+}(\mathrm{m} / \mathrm{z}$ $445) \rightarrow\left[1+\mathrm{H}-\mathrm{NH}_{3}\right]^{+}\left(\mathrm{m} / z\right.$ 428) $\rightarrow\left[\mathbf{1}+\mathrm{H}-\mathrm{NH}_{3}-\right.$ $\left.\mathrm{H}_{2} \mathrm{O}\right]^{+}\left(m / z\right.$ 410) $\left(\mathrm{ESI}(+)-\mathrm{MS}^{2}\right.$ and $-\mathrm{MS}^{3}$ not shown). The fragmentation pathways (Scheme 1), especially the water loss involving the hydroxyl group bound at the C6 atom, were proposed based on previous results described in literature [29-31].

Although the degradation process was monitored in intervals of 20 min, only the ESI(+)-MS obtained after reaction times of 80 and $140 \mathrm{~min}$ are displayed in Figures $4 \mathrm{~b}$ and $4 \mathrm{c}$, respectively. Note that the relative intensity of the ion $[\mathbf{1}+\mathrm{H}]^{+}$of $\mathrm{m} / \mathrm{z} 445$ decreases considerably as the reaction proceeds, whereas two new and intense ions of $\mathrm{m} / \mathrm{z} 461$ and 477 are clearly detected. These data indicate a continuous consumption of tetracycline (1) in solution, as was also verified in the previously described HPLC-UV and UV-Vis data, with the concomitant formation of the oxidation products 2 and 3, as shown in Scheme 2 (the proposed mechanism for the formation of both products is discussed later in this paper). For longer reaction times, the ESI(+)-MS (not shown) revealed that the intensity of the $[2+\mathrm{H}]^{+}$ ion (of $\mathrm{m} / \mathrm{z} 461$ ) continuously decreased whereas the intensity of the $[3+\mathrm{H}]^{+}$ion (of $m / z 477$ ) concomitantly increased. These results thus indicate that Compound 3 was continuously formed via a probable oxidation of 2 . In addition, it seems that no extensive degradation of 3 occurred under these reaction conditions.

As represented in Scheme 1, the mass-selection and fragmentation of the ions of $m / z 461\left([2+\mathrm{H}]^{+}\right)$and 477 $\left([3+\mathrm{H}]^{+}\right)\left(\mathrm{ESI}(+)-\mathrm{MS}^{2}\right.$ not shown) yielded mainly product ions arising from the loss of $\mathrm{NH}_{3}(\mathrm{~m} / \mathrm{z} 444$ and 460, respectively). Also note in Scheme 1 a remarkable difference in the fragmentation of the ion $[1+\mathrm{H}-$ $\left.\mathrm{NH}_{3}\right]^{+}(\mathrm{m} / \mathrm{z} 428)$, which dissociates mainly via the loss of $\mathrm{H}_{2} \mathrm{O}$, and the structurally analogous ions [2 $+\mathrm{H}-$ $\left.\mathrm{NH}_{3}\right]^{+}(m / z 444) /\left[3+\mathrm{H}-\mathrm{NH}_{3}\right]^{+}(m / z$ 460), which fragment predominantly via the release of $\mathrm{CO}_{2}$. A reasonable, but not definite explanation for such discrepancy could be proposed taking into account that the ion $\left[1+\mathrm{H}-\mathrm{NH}_{3}\right]^{+}$, which contains a hydroxyl group at position $\mathrm{C} 6$, loses water to form a highly stabilized carbocation [31, 32]. However, in the $\left[2+\mathrm{H}-\mathrm{NH}_{3}\right]^{+}$ and $\left[3+\mathrm{H}-\mathrm{NH}_{3}\right]^{+}$ions, strong hydrogen bonds could be formed between the hydroxyl groups connected at the C6 and C11a atoms, although not easily visualized in the structures as represented in Scheme $\mathbf{1}$. This could hamper the expected water loss and, as a consequence, promote the unusual and less-favorable $\mathrm{CO}_{2}$ release.

Other ions, also detected in ESI(+)-MS (Figure $4 \mathrm{~b}$ and c), are assumed to be $[\mathbf{1}+\mathrm{Na}]^{+}(m / z 467),[2+\mathrm{Na}]^{+}$ $(\mathrm{m} / \mathrm{z} 483)$, and $[3+\mathrm{Na}]^{+}(\mathrm{m} / \mathrm{z} 499)$. The ion of $\mathrm{m} / \mathrm{z} 444$ results from the dissociation of the ion $[2+\mathrm{H}]^{+}$, as confirmed by the CID experiments (not shown).

\section{LC-APCI-MS Analyses}

To confirm the results, the reaction aliquots were also analyzed by LC-APCI(+)-MS. The choice of APCI rather than ESI source is because typical APCI conditions can prevent an interface obstruction usually caused by the required use of oxalic acid (a nonvolatile compound) in the LC mobile phase [33]. Figure 5 displays the total ion chromatograms (TIC) of (a) the tetracycline aqueous solution and of aliquots taken at (b) $30 \mathrm{~min}$, (c) $90 \mathrm{~min}$, (d) $150 \mathrm{~min}$. Note that the chromatogram profiles are quite similar to those obtained by HPLC-UV analyses (Figure 2). The $\mathrm{APCI}(+)-\mathrm{MS}$ of the main chromatographic peaks are also shown in Figure 5. The presence of a prominent ion of $m / z 445$ in the APCI(+)-MS reveals that tetracycline (1) is the compound that elutes at ca. $24.0 \mathrm{~min}$. The 


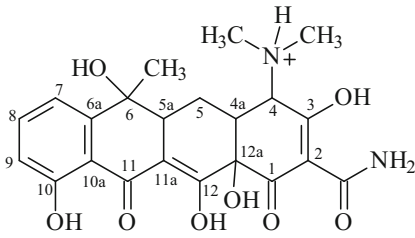

$[1+\mathrm{H}]^{+} m / z 445$

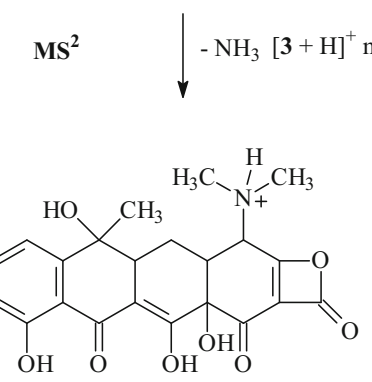

$\left[1+\mathrm{H}-\mathrm{NH}_{3}\right]^{+} m / z 428$
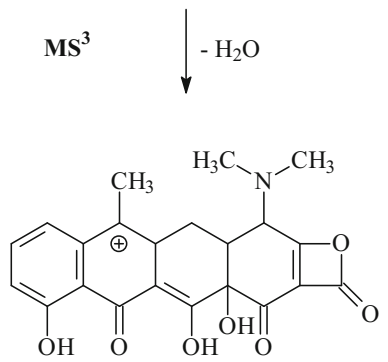

$\left[1+\mathrm{H}-\mathrm{NH}_{3}-\mathrm{H}_{2} \mathrm{O}\right]^{+} m / z 410$

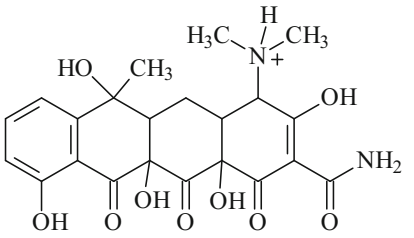

$[2+\mathrm{H}]^{+} m / z 461$

$\downarrow-\mathrm{NH}_{3}$

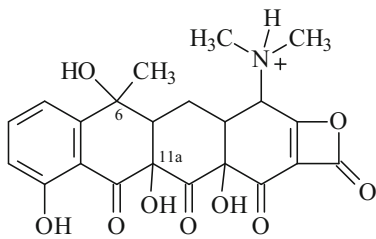

$\left[2+\mathrm{H}-\mathrm{NH}_{3}\right]^{+} m / z 444$
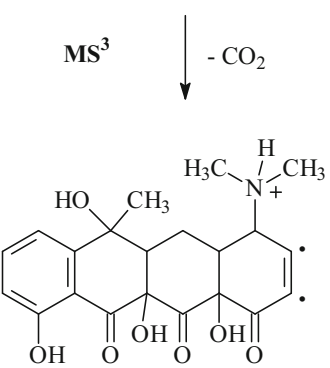

$\left[2+\mathrm{H}-\mathrm{NH}_{3}-\mathrm{CO}_{2}\right]^{+} m / z 400$

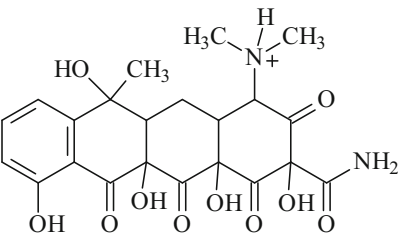

$[3+\mathrm{H}]^{+} m / z 477$

MS $^{2} \downarrow-\mathrm{NH}_{3}$

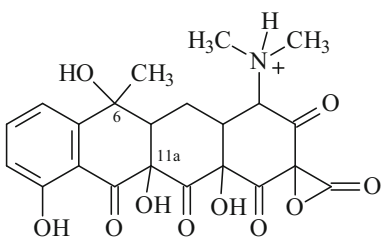

$\left[3+\mathrm{H}-\mathrm{NH}_{3}\right]^{+} m / z 460$
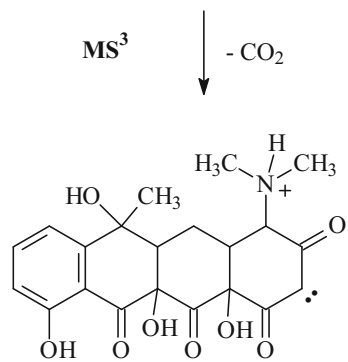

$\left[3+\mathrm{H}-\mathrm{NH}_{3}-\mathrm{CO}_{2}\right]^{+} m / z 416$

Scheme 1. Fragments proposed to be formed upon the mass-selection and collision-induced dissociation (CID) of the precursor ions $[\mathbf{1}+\mathrm{H}]^{+}(m / z 445),[2+\mathrm{H}]^{+}(m / z 461)$, and $[3+\mathrm{H}]^{+}(m / z 477)$, and their respective product ions $\left[\mathbf{1}+\mathrm{H}-\mathrm{NH}_{3}\right]^{+}(m / z 428),\left[2+\mathrm{H}-\mathrm{NH}_{3}\right]^{+}(m / z 444)$, and $[3+\mathrm{H}-$ $\left.\mathrm{NH}_{3}\right]^{+}(m / z 460)$.

APCI(+)-MS also reveals that the other relevant chromatographic peaks, i.e., with retention times of ca. 21.0 and $14.5 \mathrm{~min}$, are likely related to the oxidation products 2 (detected as the protonated molecule of $m / z 461$ ) and 3 (identified by the major presence of the ion of $\mathrm{m} / \mathrm{z}$ 477), respectively (Figure 5). These findings thus corroborate the results obtained by direct ESI(+)-MS analyses. The ion of $m / z 449$, detected in the APCI $(+)-M S$ of the compound assumed to be 3 , is suggested to be formed via an extrusion of $\mathrm{CO}$ from the ion $[3+\mathrm{H}]^{+}$of $\mathrm{m} / \mathrm{z} 477$ probably induced by successive collisions with the buffer gas or even owing to the high-temperature conditions of the APCI ion source $\left(450^{\circ} \mathrm{C}\right)$ (Scheme 3). Single ion chromatograms (SIC, not shown), obtained by the monitoring of the ions of $m / z 461$ and 477, revealed that each chromatographic peak, assumed to be related to Compounds 2 and 3, was split in a by far predominant peak and other minor peaks. These results are thus consistent with the presence of diastereoisomers that are expected to be present in solution upon the reaction of $\mathbf{1}$ with ozone, as shown in Scheme 2 .

Recent reports have shown that other advanced oxidative processes (AOP), such as $\mathrm{UV}$ and $\mathrm{TiO}_{2} / \mathrm{UV}$, also promote the degradation of tetracycline in aqueous solution but lead to a different set of products [34-37]. The oxidation products 2 and 3, assumed to be formed upon the ozonation of tetracycline (Scheme 2), have not been previously detected in similar degradation procedures using a number of AOP.

\section{Ozonation of Tetracycline: Mechanism} and Product Structures

In water solution, ozone can react with organic compounds via: (1) direct 1,3-dipolar cycloaddition to dou- 
<smiles>CN(C)C1C(O)=C(C(N)=O)C(=O)C2(O)C(O)=C3C(=O)c4c(O)cccc4C(C)(O)C3C[C@H]12</smiles>

tetracycline (1)

$[\mathbf{1}+\mathrm{H}]^{+} m / z 445$<smiles>CN(C)C1C(=O)C(O)(C(N)=O)C(=O)C2(O)C(=O)C3(O)C(=O)c4c(O)cccc4C(C)(O)C3CC12</smiles>

3

$[3+\mathrm{H}]^{+} \mathrm{m} / \mathrm{z} 477$<smiles>CN(C)C1C(O)=C(C(N)=O)C(=O)C2(O)C(=O)C3(O)C(=O)c4c(O)cccc4C(C)(O)C3CC12</smiles>

2

$[2+\mathrm{H}]^{+} m / z 461$

Scheme 2. Reaction pathways proposed for the formation of products 2 and 3 upon the reaction of tetracycline (1) with ozone in aqueous solution. Ions quoted under the structures are those detected by ESI(+)-MS or LC-APCI(+)-MS.

ble bonds $(\mathrm{C}=\mathrm{C}, \mathrm{C}=\mathrm{N}, \mathrm{N}=\mathrm{N})$; and (2) in situ generation of hydroxyl radicals [38], reactive species formed during ozone decomposition specially at high $\mathrm{pH}$ [39] (note that such specific $\mathrm{pH}$ conditions were not employed in our experimental setup as described in Experimental section). Therefore, the formation of the oxidation product 2 is proposed to involve an initial 1,3-dipolar cycloaddition of ozone, an electrophilic specie, towards the $\mathrm{C} 11 \mathrm{a}-\mathrm{C} 12$ double-bond of $\mathbf{1}$ to yield an unstable ozonide intermediate [40], which in fact was not detected during the ESI(+)-MS monitoring (Scheme 4). Note that the C11a-C12 double-bond, which is connected to only one electron-withdrawing substituent (the carbonyl group), is proposed to be much more susceptible to the ozone attack than the other available double-bond (C2-C3) of 1, which bears two carbonyl groups [41, 42]. The transient ozonide is proposed to quickly decompose, via the release of an $\mathrm{O}_{2}$ molecule, to generate an unstable epoxide intermediate. The formation of epoxides during ozonation is a well-known process that becomes especially important when bulky substituents are connected to the double bonds [43], as is the case of both double bonds in tetracycline. Finally, this epoxide is suggested to quickly undergo a rearrangement, facilitated by the presence of a hydroxyl group at position $\mathrm{C} 12$, to form product 2 . The formation of product 3 is proposed to occur via the reaction of ozone at the $\mathrm{C} 2-\mathrm{C} 3$ double-bond of 2 via an identical mechanism (Scheme 4).

The formation of diverse oxidized products by the reaction of ozone at the benzene ring of $\mathbf{1}$, another possible reactive site [44], was not taken into account since aromatic compounds are much less prompt to ozone attack than conventional olefins especially at the mild conditions employed herein [45]. Furthermore, the formation of additional products via the insertion of oxygen atoms at different positions of $\mathbf{1}$ was also not proposed owing to the lack of sites in this molecule which could be promptly attacked by ozone. A similar argument explains why Compound 3 seemed not to undergo extensive degradation under these mild conditions. In addition, it must be said that other examples on selective oxidation of pharmaceuticals at specific sites by aqueous ozone have already been reported [9].

Finally, it is important to mention that the oxygen atoms of the keto-carbonyl and hydroxyl groups seem to play a major role in the antibacterial activity of tetracycline (1), although the complete mechanism is not known so far [46]. The oxidation products 2 and 3 can probably exhibit a similar (or even higher) activity than that of $\mathbf{1}$ since these critical sites, i.e., the oxygen atoms of the keto-carbonyl and hydroxyl groups, are preserved in their structures. For instance, it has been reported that 9-hydroxytetracycline has a larger antibiotic activity in comparison to that of tetracycline [47]. However, their higher polarities, and hence higher solubilities in water in comparison to that of $\mathbf{1}$, can facilitate their distribution through the environment with serious and unpredictable consequences. 


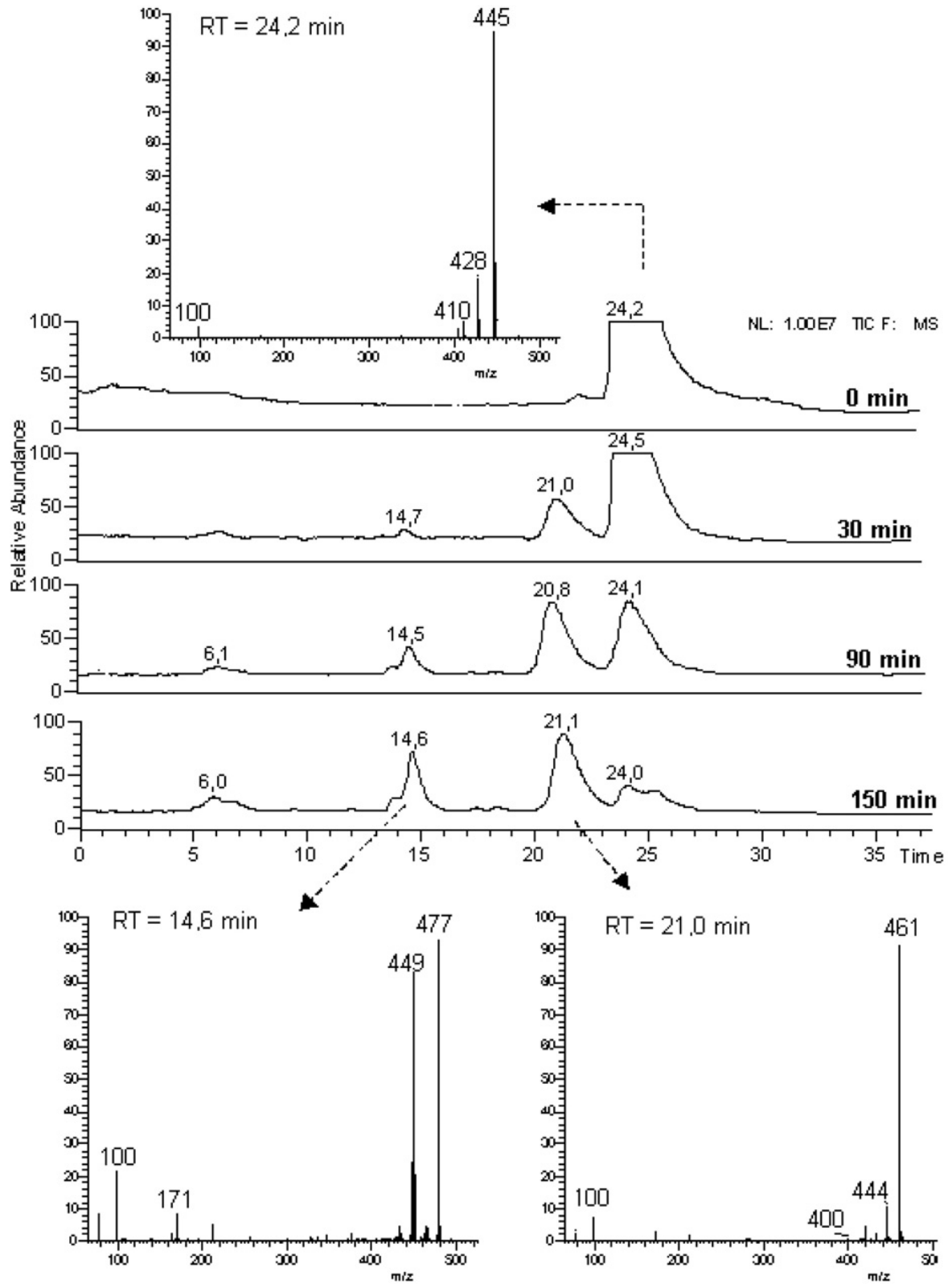

Figure 5. LC-APCI(+)-MS total ion chromatograms for the monitoring of the degradation of tetracycline by $\mathrm{O}_{3}$ in aqueous medium (aliquots withdraw after reaction times of $0,30,90$, and 150 $\mathrm{min}$ ). The insets show the mass spectra of the compounds eluted at 24.2, 21.0, and $14.6 \mathrm{~min}$.<smiles>C[NH+](C)C1C(=O)C(O)(C(N)=O)C(=O)C2(O)C(=O)C3(O)C(=O)c4c(O)cccc4C(C)(O)C3CC12</smiles>

$$
[3+\mathrm{H}]^{+} m / z 477
$$

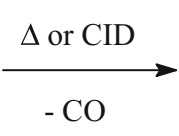<smiles>C[NH+](C)C1C2CC3C(O)(C(=O)c4c(O)cccc4C3(C)O)C(=O)C2(O)C(=O)C1(O)C(N)=O</smiles>

$m / z 449$

Scheme 3. Formation of the ion of $m / z 449$ via the extrusion of $\mathrm{CO}$ from the ion $[3+\mathrm{H}]^{+}$of $m / z 477$. 
<smiles>CN(C)C1C(O)=C(C(N)=O)C(=O)C2(O)C(O)=C3C(=O)c4c(O)cccc4C(C)(O)C3CC12</smiles>

tetracycline $(1 ; 444 \mathrm{Da})$<smiles>CN(C)C1C(O)=C(C(N)=O)C(=O)C2(O)C1CC1C(C)(O)c3cccc(O)c3C(=O)C12O</smiles>

epoxide intermediate<smiles>CN(C)C1C2CC3C(O)(C(=O)c4c(O)cccc4C3(C)O)C(=O)C2(O)C(=O)C2(C(N)=O)OC12O</smiles>

epoxide intermediate<smiles>CN(C)C1C(O)=C(C(N)=O)C(=O)C2(O)C3CC4(O)C1(OC24O)C(=O)c1c(O)cccc1C3(C)O</smiles>

ozonide intermediate<smiles>CN(C)C1C(O)=C(C(N)=O)C(=O)C2(O)C(=O)C3(O)C(=O)c4c(O)cccc4C(C)(O)C3CC12</smiles>

$2(460 \mathrm{Da})$

$3(476 \mathrm{Da})$

Scheme 4. Reaction mechanism proposed for the formation of products 2 and 3 upon the reaction of tetracycline (1) with ozone in aqueous solution.

\section{Conclusions}

As clearly revealed by the ESI-MS and LC-APCI-MS analyses, in conjunction with the HPLC-UV, UV-Vis, and TOC data, tetracycline (1) quickly reacts with $\mathrm{O}_{3}$ in aqueous solution to presumably form the oxidized derivatives 2 via an initial 1,3-dipolar cycloaddition of ozone at the C11a-C12 double-bond of 1, and 3 by a subsequent ozone attack at the C2-C3 double bonds of 2 . Such results thus indicate that $\mathrm{O}_{3}$ promotes neither the mineralization of tetracycline nor the formation of sideproducts by extensive ring breakdown, at least under the mild conditions employed herein. The extraordinary ability of ESI-MS to transfer short-lived and highly polar intermediates, such as $\mathbf{2}$ and $\mathbf{3}$, directly from the aqueous solution to the gas-phase allowed their prompt detection and characterization (via ESI-MS ${ }^{n}$ ). Furthermore, the detection of products 2 and 3 by GC-MS, the most traditional technique usually employed to analyze reaction mixtures, would be much more difficult owing to the complex and time-consuming procedures required [48]. Finally, additional studies are required to verify whether the two main oxidation products ( 2 and 3) could cause serious environmental damages.

\section{Acknowledgments}

The authors thank the Fundação de Amparo à Pesquisa do Estado de Minas Gerais (FAPEMIG) and the Conselho Nacional de Desenvolvimento Cientiifico e Tecnológico (CNPq) for the financial support and research fellowships. The authors are also indebted to Dr. Francisco A. R. Barbosa (ICB-UFMG), who has kindly allowed their group to use his TOC instrument for the last two years.

\section{References}

1. Daughton, C. G.; Ternes, T. A. Pharmaceuticals and Personal Care Products in the Environment: Agents of Subtle Change? Environ. Health Perspect. 1999, 107, 907-938. 
2. Heberer, T. Occurrence, Fate, and Removal of Pharmaceutical Residues in the Aquatic Environment: A Review of Recent Research Data. Toxicol. Lett. 2002, 131, 5-17.

3. Kolpin, D. W.; Skopec, M.; Meyer, M. T.; Furlong, E. T.; Zaugg, S. D. Urban Contribution of Pharmaceuticals and Other Organic Wastewater Contaminants to Streams During Differing Flow Conditions. Sci. Tot. Environ. 2004, 328, 119-130.

4. Halling-Sorensen, B.; Lykkeberg, A.; Ingerslev, F.; Blackwell, P.; Tjornelund, J. Characterization of the Abiotic Degradation Pathways of Oxytetracyclines in Soil Interstitial Water Using LC-MS-MS. Chemosphere 2003, 50, 1331-1342.

5. Gogate, P. R.; Pandit, A. B. A Review of Imperative Technologies for Wastewater Treatment. I. Oxidation Technologies at Ambient Conditions. Adv. Environ. Res. 2004, 8, 501-551.

6. Gogate, P. R.; Pandit, A. B. A Review of Imperative Technologies for Wastewater Treatment. II. Hybrid Methods. Adv. Environ. Res. 2004, 8, 553-597.

7. Ternes, T. A.; Meisenheimer, M.; McDowell, D.; Sacher, F.; Brauch, H. J.; Gulde, B. H.; Preuss, G.; Wilme, U.; Seibert, N. Z. Removal of Pharmaceuticals During Drinking Water Treatment. Environ. Sci. Technol. 2002, $36,3855-3863$

8. Hernando, M. D.; Mezcua, M.; Fernandez-Alba, A. R.; Barcelo, D. Environmental Risk Assessment of Pharmaceutical Residues in Wastewater Effluents, Surface Waters, and Sediments. Talanta 2006, 69, 334-342.

9. Huber, M. M.; Canonica, S.; Park, G. Y.; Von Gunten, U. Oxidation of Pharmaceuticals During Ozonation and Advanced Oxidation Processes. Environ. Sci. Technol. 2003, 37, 1016-1024.

10. Huber, M. M.; Gobel, A.; Joss, A.; Hermann, N.; Loffler, D.; Mcardell, C. S.; Ried, A.; Siegrist, H.; Ternes, T. A.; von Gunten, U. Oxidation of Pharmaceuticals During Ozonation of Municipal Wastewater Effluents: A Pilot Study. Environ. Sci. Technol. 2005, 39, 4290-4299.

11. Ternes, T. A.; Stuber, J.; Herrmann, N.; McDowell, D.; Ried, A.; Kampmann, M.; Teiser, B. Ozonation: A Tool for Removal of Pharmaceuticals, Contrast Media, and Musk Fragrances from Wastewater? Water Res. 2003, 37, 1976-1982.

12. Watkins, B. D.; Hengemuehle, S. M.; Person, H. L.; Yokoyama, M. T.; Masten, S. J. Ozonation of Swine Manure Wastes to Control Odors and Reduce the Concentrations of Pathogens and Toxic Fermentation Metabolites. Ozone Sci. Eng. 1997, 19, 425-437.

13. Chopra, I.; Roberts, M. Tetracycline antibiotics: Mode of Action, Applications, Molecular Biology, and Epidemiology of Bacterial Resistance. Microbiol. Mol. Biol. Rev. 2001, 65, 232-233.

14. Hamscher, G.; Sczesny, S.; Hoper, H.; Nau, H. Determination of Persistent Tetracycline Residues in Soil Fertilized with Liquid Manure by High-Performance Liquid Chromatography with Electrospray Ionization Tandem Mass Spectrometry. Anal. Chem. 2002, 74, 1509-1518.

15. Karthikeyan, K. G.; Meyer, M. T. Occurrence of Antibiotics in Wastewater Treatment Facilities in Wisconsin, U.S.A. Sci. Tot. Environ. 2006, 361, 196-207.

16. Diaz-Cruz, M. S.; de Alda, M. J. L.; Barcelo, D. Environmental Behavior and Analysis of Veterinary and Human Drugs in Soils, Sediments, and Sludge. Trends Anal. Chem. 2003, 22, 340-351.

17. Domingos, J. B.; Longhinotti, E.; Brandao, T. A. S.; Bunton, C. A.; Santos, L. S.; Eberlin, M. N.; Nome, F. Mechanisms of Nucleophilic Substitution Reactions of Methylated Hydroxylamines with bis(2,4-Dinitrophenyl) Phosphate. Mass Spectrometric Identification of Key Intermediates. J. Org. Chem. 2004, 69, 6024-6033.

18. Meurer, E. C.; Sabino, A. A.; Eberlin, M. N. Ionic Transacetalization with Acylium Ions: A Class-Selective and Structurally Diagnostic Reaction for Cyclic Acetals Performed Under Unique Electrospray and Atmospheric Pressure Chemical Ionization In-Source Ion-Molecule Reaction Conditions. Anal. Chem. 2003, 75, 4701-4709.

19. Meyer, S.; Koch, R.; Metzger, J. O. Investigation of Reactive Intermediates of Chemical Reactions in Solution by Electrospray Ionization Mass Spectrometry: Radical Cation Chain Reactions. Angew. Chem. Int. Ed. 2003, 42, 4700-4703.

20. Santos, L. S.; Knaack, L.; Metzger, J. O. Investigation of Chemical Reactions in Solution Using API-MS. Int. J. Mass Spectrom. 2005, 246, 84-104.

21. Madeira, P.; Nunes, M. R.; Borges, C.; Costa, F. M. A.; Florencio, M. H. Benzidine Photodegradation: A Mass Spectrometry and UV Spectroscopy Combined Study. Rapid Commun. Mass Spectrom. 2005, 19, 20152020.

22. Florencio, M. H.; Pires, E.; Castro, A. L.; Nunes, M. R.; Borges, C.; Costa, F. M. Photodegradation of Diquat and Paraquat in Aqueous Solutions by Titanium Dioxide: Evolution of Degradation Reactions and Characterization of Intermediates. Chemosphere 2004, 55, 345-355.

23. Hess, T. F.; Renn, T. S.; Watts, R. J.; Paszczynski, A. J. Studies on Nitroaromatic Compound Degradation in Modified Fenton Reactions by Electrospray Ionization Tandem Mass Spectrometry (ESI-MS-MS). Analyst 2003, 128, 156-160.
24. Dalmazio, I.; Santos, L. S.; Lopes, R. P.; Eberlin, M. N.; Augusti, R. Advanced Oxidation of Caffeine in Water: On-Line and Real-Time Monitoring by Electrospray Ionization Mass Spectrometry. Environ. Sci. Technol. 2005, 39, 5982-5988.

25. Santos, L. S.; Dalmazio, I.; Eberlin, M. N.; Claeys, M.; Augusti, R Mimicking the Atmospheric OH-Radical-Mediated Photooxidation of Isoprene: Formation of Cloud-Condensation Nuclei Polyols Monitored by Electrospray Ionization Mass Spectrometry. Rapid Commun. Mass Spectrom. 2006, 20, 2104-2108.

26. Moura, F. C. C.; Araujo, M. H.; Dalmazio, I.; Alves, T. M. A.; Santos, L. S.; Eberlin, M. N.; Augusti, R.; Lago, R. M. Investigation of Reaction Mechanisms by Electrospray Ionization Mass Spectrometry: Characterization of Intermediates in the Degradation of Phenol by a Nove Iron/Magnetite/Hydrogen Peroxide Heterogeneous Oxidation System. Rapid Commun. Mass Spectrom. 2006, 20, 1859-1863.

27. Kotiaho, T.; Eberlin, M. N.; Vainiotalo, P.; Kostiainen, R. Electrospray Mass and Tandem Mass Spectrometry Identification of Ozone Oxidation Products of Amino Acids and Small Peptides. J. Am. Soc. Mass Spectrom. 2000, 11, 526-535.

28. Jardim, W. F.; Moraes, S. G.; Takiyama, M. M. K. Photocatalytic Degradation of Aromatic Chlorinated Compounds Using $\mathrm{TiO}_{2}$ : Toxicity of Intermediates. Water Res. 1997, 31, 1728-1732.

29. Kamel, A. M.; Brown, P. R.; Munson, B. Electrospray Ionization Mass Spectrometry of Tetracycline, Oxytetracycline, Chlorotetracycline, Minocycline, and Methacycline. Anal. Chem. 1999, 71, 968-977.

30. Kamel, A. M.; Fouda, H. G.; Brown, P. R.; Munson, B. Mass Spectral Characterization of Tetracyclines by Electrospray Ionization, H/D Exchange, and Multiple Stage Mass Spectrometry. J. Am. Soc. Mass Spectrom. 2002, 13, 543-557.

31. Vartanian, V. H.; Goolsby, B.; Brodbelt, J. S. Identification of Tetracycline Antibiotics by Electrospray Ionization in a Quadrupole Ion Trap. J. Am. Soc. Mass Spectrom. 1998, 9, 1089-1098.

32. Oka, H.; Ito, Y.; Ikai, Y.; Kagami, T.; Harada, K. Mass Spectrometric Analysis of Tetracycline Antibiotics in Foods. J. Chromatogr. A 1998, 812, 309-319.

33. Nakazawa, H.; Ino, S.; Kato, K.; Watanabe, T.; Ito, Y.; Oka, H. Simultaneous Determination of Residual Tetracyclines in Foods by HighPerformance Liquid Chromatography with Atmospheric Pressure Chemical Ionization Tandem Mass Spectrometry. J. Chromatogr. B 1999, 732, 55-64.

34. Oka, H.; Ikai, Y.; Kawamura, N.; Yamada, M.; Harada, K.; Ito, S.; Suzuki, M. Photodecomposition Products of Tetracycline in Aqueous Solution. J. Agric. Food Chem. 1989, 37, 226-231.

35. Di Paola, A.; Addamo, M.; Augugliaro, V.; Garcia-Lopez, E.; Loddo, V.; Marci, G.; Palmisano, L. Photolytic and $\mathrm{TiO}_{2}$-Assisted Photodegradation of Aqueous Solutions of Tetracycline. Fresenius Environ. Bull. 2004, $13,1275-1280$.

36. Addamo, M.; Augugliaro, V.; Di Paola, A.; Garcia-Lopez, E.; Loddo, V.; Marci, G.; Palmisano, L. Removal of Drugs in Aqueous Systems by Photoassisted Degradation. J. Appl. Electrochem. 2005, 35, 765-774.

37. Hasan, T.; Allen, M.; Cooperman, B. S. Anhydrotetracycline is a Major Product of Tetracycline Photolysis. J. Org. Chem. 1985, 50, 1755-1757.

38. Hoigne, J.; Bader, H. Role of Hydroxyl Radical Reactions in Ozonation Processes in Aqueous Solutions. Water Res. 1976, 10, 377-386.

39. Glaze, W. H. Drinking-Water Treatment with Ozone. Environ. Sci. Technol. 1987, 21, 224-230.

40. Gillies, J. Z.; Gillies, C. W.; Suenram, R. D.; Lovas, F. J. The ozonolysis of ethylene. Microwave-spectrum, molecular-structure, and dipolemoment of ethylene primary ozonide (1,2,3-trioxolane). J. Am. Chem Soc. 1988, 110, 7991-7999.

41. Pryor, W. A.; Giamalva, D.; Church, D. F. Kinetics of Ozonation. 1. Electron-Deficient Alkenes. J. Am. Chem. Soc. 1983, 105, 6858-6861.

42. Pryor, W. A.; Giamalva, D.; Church, D. F. Kinetics of Ozonation. 3. Substituent Effects on the Rates of Reaction of Alkenes. J. Am. Chem. Soc. 1985, 107, 2793-2797.

43. Bailey, P. S.; Hwang, H. H.; Chiang, C. Y. Mechanisms of Epoxidation During Ozonation of Carbon-Carbon Double Bonds. J. Org. Chem. 1985, 50, 231-234.

44. Dodd, M. C.; Buffle, M. O.; Von Gunten, U. Oxidation of Antibacterial Molecules by Aqueous Ozone: Moiety-Specific Reaction Kinetics and Application to Ozone-Based Wastewater Treatment. Environ. Sci. Technol. 2006, 40, 1969-1977.

45. Omurchu, C. Ozonolysis of Quinolines: A Versatile Synthesis of Polyfunctional Pyridines. Synthesis 1989, 880-882.

46. Brodersen, D. E.; Clemons, W. M.; Carter, A. P.; Morgan-Warren, R. J.; Wimberly, B. T.; Ramakrishnan, V. The Structural Basis for the Action of the Antibiotics Tetracycline, Pactamycin, and Hygromycin B on the $30 \mathrm{~S}$ Ribosomal Subunit. Cell 2000, 103, 1143-1154.

47. Shu, P. Oxidative Preparation of 9-Hydroxytetracyclines. J. Am. Chem Soc. 1966, 88, 4529-4530.

48. Barker, S. A.; Walker, C. C. Chromatographic Methods for Tetracycline Analysis in Foods. J. Chromatogr. 1992, 624, 195-209. 